\title{
Editorial
}

\section{Commitment to Excellence: Upholding Research Integrity at Management and Organization Review}

\author{
Anne S. Tsui ${ }^{1,2}$ and Joseph Galaskiewicz ${ }^{3}$ \\ 'Arizona State University, USA, ${ }^{2}$ Peking University, China, and ${ }^{3}$ University of Arizona, USA
}

\section{INTRODUCTION}

This Editors' Forum presents a topic that has received much attention in all sciences and is of great importance to both the International Association for Chinese Management Research (IACMR) and Management and Organization Review $(M O R)$. From the beginning, the IACMR developed a code of ethics covering ethical and professional conduct in research, publications, and conferences. We refer to this code in a statement titled the 'Commitment to Excellence'. This statement is published on the IACMR website and in the first issue of each volume of $M O R$, and it is also sent to new members who join the IACMR and to current members who renew their membership. The expectations of ethical behaviour are also stated in the Call for Submissions to the biennial IACMR conference. Included is a discussion of research ethics in the biennial research methods workshop for doctoral students and young faculty members, and it is a part of the IACMR's new member orientation. In a recent survey of science journals, Resnik, Patrone, \& Peddada (2010) reported that less than half of the journals they studied reported that they had a formal misconduct policy, but those that did had higher impact factor scores. This suggests that the IACMR and MOR are 'ahead of the game' and in good company on this issue.

The purpose of this Editors' Forum, guest edited by Marshall Schminke and Maureen Ambrose, is part of our ongoing effort to provide research ethics education to the Chinese management research community. Since research ethics training is not a required or systematic part of business school's master and doctoral education in China, the IACMR assumes the responsibility to define and disseminate ethical research practices among its members (see Mowday, 2011, for a brief discussion of the Academy of Management experience with its 
code of ethics). Through education and members' self-enforcement, we aspire to become a community of scholars who embody the ethical principles in our research conduct and in so doing ensure that the knowledge created through our research is truly original and valid.

In this Editors' Forum, the aim is not to discuss the blatant misconduct that is discussed in research methods books and/or publicised in newspapers (see, for example, the New York Times article, 'Rampant fraud threat to China's brisk ascent', published 6 October 2010). The purpose of this Forum is to discuss the many situations that fall into 'grey areas' that may have unclear ethical implications (for example, post hoc theorizing, see Leung, 2011). The purpose of this Editorial is to describe the process used by MOR to ensure that the articles published in this journal meet the standards of research ethics that is the bedrock of our profession. There is a substantial literature on research ethics related to publications, and we cannot cover all the topics here. For example, there are papers on the ethics of peer review (Souder, 2011), withholding commissioned research from publication (Ham, 1999), 'shotgunning' (sending papers to more than one journal at a time) (Rogers, 1999), and what copyright laws say about the publication of others' works (Jeffery \& Fries, 2011). We encourage readers to explore this important literature.

\section{THIS FORUM}

This Editors' Forum is not about extreme and obvious transgressions such as reporting false results, stealing ideas from others, deliberately copying published or unpublished texts without citing the original sources, fabricating data to fit the hypotheses, or publishing the same paper involving the same idea in two or more different outlets. Instead, it brings to light situations that are relatively more ambiguous in their ethical implications, and that may not have clear guidelines on how to deal with them. The ten essays in total (eight articles on eight different substantive topics, along with a commentary, and the guest editors' introduction) cover a wide spectrum of issues. The guest editors' Introduction provides an overview of these nine essays and so they will not be repeated here. We thank the authors for their contribution to the discussion of these important topics and in helping to clarify some of the ambiguous areas. In particular, the Introduction (Schminke \& Ambrose, 2011) reveals the many ethical dilemmas that authors may encounter on the research and publishing journey and corrects some myths about ethical (or non-ethical) behaviours. Together, as the guest editors conclude, this Forum 'comprise[s] a tour de force regarding research and publication ethics, not simply because they were written by some of the top scholars in our field, but more importantly they are written by some of the top citizens of our field' (Schminke \& Ambrose, 2011: 405). 


\section{ENSURING RESEARGH INTEGRITY IN MANUSCRIPTS SUBMITTED TO MOR}

The $M O R$ editors begin with the assumption that all research reported in the submitted manuscripts is original since we ask the authors to pledge to its originality before submission. However, we also recognise that many of MOR's authors may not have systematic training in research methods and are not well aware of the ethical requirements. For example, about ten years ago, I was asked by a professor in China how she should respond to a question by a student. The student asked if he could change the data so that his hypotheses would be supported in his master's thesis. I was more horrified by the professor's question to me than by the student's question to her. Clearly, the professor did not understand the purpose of research and that data constitute empirical fact. As Charles Darwin said, 'False facts are highly injurious to the progress of science' (Ayala, 2009: 10039). Mentors play an important role in ensuring the proper conduct of research by students and trainees and need to assume responsibility in these cases (Lee \& Mitchell, 2011; Wright, Titus, \& Cornelison, 2008).

After ten years' progress in the development of the management research community in China, we are sure researchers now know that falsifying data, plagiarism, and data fabrication are scientific 'crimes' that can result in loss of employment, censure by professional associations, retraction, and loss of funding. The Chinese government, NGOs, and universities have recognised that scientific misconduct is a problem and have taken measures to rectify the situation (Zeng \& Resnik, 2010), although there is some evidence (based on an analysis of 788 English language research papers retracted from the PubMed database between 2000 and 2010) that China does not appear to have bigger problems with research fraud than other countries (Steen, 2011).

A common challenge for many MOR authors today is in writing manuscripts and getting published in top quality journals. Since English is not their native language, many of them use the 'copy or imitate' approach to writing papers in English. Some authors simply do not know how many words they can cut and paste from other articles to stay within the bounds of acceptability. Other authors naively believe that it is acceptable to use passages from other papers that they have written themselves in a new paper without referencing the earlier papers. After all, they are the authors of both papers and so they are not violating the intellectual property rights of another person. Authors also often believe that using the same data from the same research study and analysing or presenting the data in a similar way in two different papers is acceptable. However, a recent survey of Wiley-Blackwell science journals cited these 'redundant publications (i.e., overlapping or "salami", publications)' as the biggest problem they faced (Wager, Fiack, Graf, Robinson, \& Rowlands, 2009: 348-349: see also Souder, 2011: 64-65; Regmi, 2011: 77; and Rogers, 1999: 265 for more discussion of salami-slicing). Kirkman and Chen (2011) in this issue explain when 
multiple publications from the same dataset are acceptable. We at MOR aim to identify these problems and correct these misperceptions through the manuscript editing and reviewing process (see Aguinis \& Vaschetto, 2011 and Rupp, 2011 for a discussion of the ethical responsibility of editors and reviewers). Through this process, $M O R$ authors can learn to avoid similar mistakes in the future (see Chen, 2011 for a discussion of author ethics in the publication process).

The publication consideration process at $M O R$ begins with subjecting the new manuscript to the 'CrossCheck' plagiarism software. The software compares the manuscript to published or unpublished work available on the Internet. Each check gives a percentage of overlap, and highlights the text that is similar to the texts in other sources. Usually, the overlaps are within acceptable limits (e.g., around 40 percent including references or 25 percent excluding them). However, we still go through the highlighted text even if there is only 1 percent overlap to ensure that there is no plagiarism. The manuscript is then passed on to the Editor in Chief (EIC) for assignment to an action editor. If the overlap is substantial, the EIC determines if the manuscript should be returned to the author to explain the overlap. So far, MOR has not had a case involving so much overlap that the manuscript has to be returned without being reviewed.

Once the manuscript is conditionally accepted after the review process, it is subjected to another plagiarism check. This is to ensure that the authors did not bring in new text during the revision process that may be taken from other sources without proper citation or attributions. Usually, papers pass this check easily but we did uncover the duplicate publication issue mentioned below.

After sending one conditionally accepted manuscript through our plagiarism check, we discovered that it had a 90 percent overlap with a chapter, by the same author, in a published book. We sent the author an inquiry about this and were informed that the conditionally accepted paper was presented at a conference. The conference organisers decided to publish a book of the papers presented at the conference. The author said that he did not know that the paper was being included in the book. The conference occurred after the paper was submitted. We asked the author to withdraw the paper since the paper was no longer original given that it had already been published. This was an unfortunate event, but it represents the nuances of the ethical issues involved with plagiarism.

The most common problem we have is 'copy cat' papers with several lines of text or an entire paragraph that is similar to published sources. In such cases, we ask the author to pursue one of two options. If the text has an important point that is best presented in its original form, we ask the author to put the text in quotation marks and cite the original source, including page numbers. More commonly, we ask the author to present the point in the author's own words. In other words, the author could paraphrase the original idea using slightly different words and cite the paper as the source of that idea. If the overlapped text is simple everyday language without an intellectual idea, we leave the text as is even though it is identical to the 
text from another source. For example, the text could be 'leadership has the most important influence on an organization's culture'. Many authors have made this point and all studies of the role of leadership on organisational culture would probably include a sentence like this. In this case, citing a source is unnecessary.

In another instance, we found an accepted paper having a large percentage of overlap with a dissertation which is available online through the library of the university where the author received his $\mathrm{PhD}$. As it turns out, this dissertation was by the author of the accepted paper. Since the dissertation was not published elsewhere, we asked the author to cite the dissertation in the paper, resolving the matter. In such a case, the author also can add a NOTE indicating that the paper is based on the author's dissertation with the title and completion date.

Although the plagiarism check ensures the originality of the content of a paper, it could not provide information on the integrity of the data used in a study. This is why we have to rely on the professionalism of the authors themselves. Occasionally, reviewers may discover that a paper's ideas or data are similar to another paper that they reviewed for another journal. Sometimes a reader may identify potential problems in a dataset or paper and write to the editor of the journal about it. MOR has had one experience that may be worthy of mentioning as another opportunity for learning. This experience reveals the sensitivity of $M O R$ readers to the integrity of the papers' ideas and data, and highlights the high standards our readers expect from $M O R$ articles.

A paper was published involving the use of a publicly available dataset. A reader observed that the data used for this paper did not seem to correspond to the reader's own knowledge of this publicly available dataset. The data were coded in a way suitable for analysis in this paper. Therefore, the reader asked the authors to explain the coding procedure so that the reader could reanalyse the data. The authors reviewed their coding and acknowledged that they had missed some cases. This led to an Erratum being published (Beamish \& Bapuji, 2009). The reader was not satisfied and proceeded to code the data in the same way that the authors explained in the paper. The reader claimed that the authors had missed more data than they had reported in the original paper or in the Erratum. This led to a Response to the Erratum (Fox, 2010), and a further response by one of the original authors (Bapuji \& Laplume, 2010).

This exchange is productive in that it highlights the importance of careful coding of data and reporting of the findings. Even if errors were missed during the review process, readers serve as monitors and rise up to point out such errors. This enforcement of the highest standards in research ethics and data integrity helps us learn and advance. Schminke and Ambrose (2011) note how they have never been asked to provide the data behind an article they wrote nor have they, as journal editors, asked authors to make their data available. However, Souder (2011: 57), extrapolating from Merton's (1973) discussion of communalism, argues that a norm of science is that scientists make their data available to the scientific 
community. We at MOR do not ask authors to make their data available to reviewers, but authors should remember that it is a legitimate option for editors.

\section{CONCLUSION}

On 6 October 2010, the New York Times reported the results of a twenty-month study on plagiarism by Zhejiang University (Jacobs, 2010). Using the same CrossCheck software that MOR employs, over a third of the submissions to Zhejiang University's collection of journals involved materials that were 'pirated' from published research. This article further reported that a third of the 6000 scientists in the top six universities in China admit 'that they had engaged in plagiarism or outright fabrication of research data' in a government study. In a study by the China Association for Science and Technology of 32,000 scientists, more than 55 percent said they knew of someone who was 'guilty of academic fraud'. This is disturbing news but we are glad about the media attention to such matters, and, as noted above, the Chinese government and universities are conducting their own studies about ethical research behaviour and establishing systems of accountability (Zeng \& Resnik, 2010). It is possible that some of the guilty parties were truly ignorant or innocent. Hopefully, with continuing attention and education, researchers will begin to understand the meaning of science and the importance of protecting its integrity for the purpose of producing valid knowledge.

The purpose of science is to seek truth; this truth can be ensured in the final outcome of our investigation only when the process or journey of pursuing this truth has integrity. As guest editors Schminke and Ambrose (2011) point out, the only auditing of our work is the review process. This review occurs at the end of the research process. Therefore, the ultimate auditors of our own work are the researchers themselves. The best enforcement of research ethics is not a post hoc audit by a third party. The best enforcement is self-monitoring and voluntary compliance to ethical standards.

\section{NOTE}

We would like to thank Kendra Thompson-Dyck, a Sociology Ph.D. student at the University of Arizona, for finding relevant bibliographic materials and checking our references.

\section{REFERENCES}

Aguinis, H., \& Vaschetto, S. J. 2011. Editorial responsibility: Managing the publishing process to do good and do well. Management and Organization Revieze, 7(3): 407-422.

Ayala, F. J 2009. Darwin and the scientific method. Proceeding of the National Academy of Sciences, 106: 10033-10039.

Bapuji, H., \& Laplume, A. 2010. Missing the forest from the trees: A reply. Management and Organization Revieze, 6(1): 157-161.

Beamish, P. W., \& Bapuji, H. 2009. Erratum. Management and Organization Revieze, 5(1): 150 . 
Chen, X. P. 2011 . Author ethical dilemmas in the research publication process. Management and Organization Review, 7(3): 423-432.

Fox, M. 2010. Erratum response to Beamish and Bapuji. Management and Organization Review, 6(1): 151-155.

Ham, V. 1999. Tracking the truth of selling one's soul? Reflections on a piece of commissioned research. British Journal of Educational Studies, 47(3): 275-282.

Jacobs, A. 2010, Oct. 6. Rampant fraud threat to China's brisk ascent. New York Times. [Last accessed 27 June 2011.] Available from URL: http://www.nytimes.com/2010/10/07/world/ asia/07fraud.html.

Jeffery, D. D., \& Fries, J. 2011. Unauthorized uses of a coauthored work and a doctoral dissertation. Ethics \& Behavior, 21(2): 118-126.

Kirkman, B. L., \& Chen, G. 2011. Maximizing your data or data slicing? Recommendations for management multiple submissions from the same dataset. Management and Organization Review, 7(3): 433-446.

Lee, T. W., \& Mitchell, T. R. 201 l. Working in research teams: Lessons from personal experiences. Management and Organization Review, 7(3): 461-469.

Leung, K. 2011. Presenting post hoc hypotheses as a priori: Ethical and theoretical issues. Management and Organization Reviere, 7(3): 471-479.

Merton, R. K. 1973. The sociology of science: Theoretical and empirical investigations. Chicago, IL: University of Chicago Press.

Mowday, R. T. 2011. Elevating the dialogue on professional ethics to the next level: Reflections on the expcrience of the Academy of Management. Management and Organization Revieze, 7(3): 505-509.

Regmi, K. 2011. Ethnical and legal issues in publication and dissemination of scholarly knowledge: A summary of the published cvidence. Joumal of Academic Ethics, 9: 71-81.

Resnik, D. B., Patrone, D., \& Peddada, S. 2010. Research misconduct policies of social science journals and impact factor. Accountability in Research, 17: 79-84.

Rogers, L. 1999. Salami slicing, shotgunning, and the ethics of authorship. American Joumal of Roentgenology, 173(2): 265.

Rupp, D. E. 2011. Ethical issues faced by editors and reviewers. Management and Organization Review, 7(3): 481-493.

Schminke, M., \& Ambrose, M. 2011 . Ethics and integrity in the publishing process: Myths, facts, and a roadmap. Management and Organization Review, 7(3): 397-406.

Souder, L. 2011. The ethics of scholarly peer review: A review of the literaturc. Learmed Publishing, 24(1): 55-74.

Steen, R. G. 2011. Retractions in the scientific literature: Do authors deliberately commit research fraud? Journal of Medical Ethics, 37: 113-117.

Wager, E., Fiack, S., Graf, C., Robinson, A., \& Rowlands, I. 2009. Science journal editors' views on publication ethics: Results of an international survey. Joumal of Medical Ethics, 35: 348353.

Wright, D. E., Titus, S. L., \& Cornelison, J. B. 2008. Mentoring and research misconduct: An analysis of research mentoring in closed ORI cases. Science and Engineering Ethics, 14: 323-336.

Zeng, W., \& Resnik, D. 2010. Research integrity in China: Problems and prospects. Developing World Bioethics, 10(3): 164-171. 